\title{
Structure and Properties of Nanocrystalline $(\mathrm{TiZr})_{x} \mathbf{N}_{1-x}$ Thin Films Deposited by DC Unbalanced Magnetron Sputtering
}

\author{
Yu-Wei Lin, ${ }^{1,2}$ Chia-Wei Lu, ${ }^{2}$ Ge-Ping Yu, ${ }^{2,3}$ and Jia-Hong Huang ${ }^{2}$ \\ ${ }^{1}$ Instrument Technology Research Center, National Applied Research Laboratories, No. 20, R\&D Road VI, \\ Hsinchu Science-Based Industrial Park, Hsinchu 300, Taiwan \\ ${ }^{2}$ Department of Engineering and System Science, National Tsing Hua University, Hsinchu 300, Taiwan \\ ${ }^{3}$ Institute of Nuclear Engineering and Science, National Tsing Hua University, Hsinchu 300, Taiwan \\ Correspondence should be addressed to Yu-Wei Lin; james722@itrc.narl.org.tw
}

Received 11 November 2015; Revised 1 February 2016; Accepted 11 February 2016

Academic Editor: Ying-Lung D. Ho

Copyright (C) 2016 Yu-Wei Lin et al. This is an open access article distributed under the Creative Commons Attribution License, which permits unrestricted use, distribution, and reproduction in any medium, provided the original work is properly cited.

This study aims to investigate the effects of nitrogen flow rate $(0-2.5 \mathrm{sccm})$ on the structure and properties of TiZrN films. Nanocrystalline TiZrN thin films were deposited on Si (001) substrates by unbalanced magnetron sputtering. The major effects of the nitrogen flow rate were on the phase, texture, $\mathrm{N} /(\mathrm{Ti}+\mathrm{Zr})$ ratio, thickness, hardness, residual stress, and resistivity of the TiZrN films. The nitrogen content played an important role in the phase transition. With increasing nitrogen flow rate, the phase changed from mixed TiZr and TiZrN phases to a single TiZrN phase. The X-ray diffraction results indicated that (111) was the preferred orientation for all TiZrN specimens. The $\mathrm{N} /(\mathrm{Ti}+\mathrm{Zr})$ ratio of the TiZrN films first increased with increasing nitrogen flow rate and then stabilized when the flow rate further increased. When the nitrogen flow rate increased from 0.4 to $1.0 \mathrm{sccm}$, the hardness and residual stress of the TiZrN thin film increased, whereas the electrical resistivity decreased. None of the properties of the TiZrN thin films changed with nitrogen flow rate above $1.0 \mathrm{sccm}$ because the films contained a stable single phase (TiZrN). At high nitrogen flow rates $(1.0-2.5 \mathrm{sccm})$, the average hardness and resistivity of the TiZrN thin films were approximately $36 \mathrm{GPa}$ and $36.5 \mu \Omega \cdot \mathrm{cm}$, respectively.

\section{Introduction}

Since the 1980s, transition metal nitride coatings produced by physical vapor deposition have been widely studied. Binary transition metal nitride films such as TiN and $\mathrm{ZrN}$ are often used as protective coatings to enhance the properties of substrate materials. Due to their high hardness and better wear and corrosion resistance, binary transition metal nitride films are widely used in industry. Additionally, transition metal nitrides are used as diffusion barriers in the semiconductor industry $[1,2]$.

With the rapid development of technology, demands for high-quality films are increasing. Therefore, development of multifunctional ternary transition metal nitride films has begun. Under equivalent deposition conditions, TiZrN coatings not only exhibit corrosion resistance and superior mechanical properties such as lower resistivity, higher adhesion, and lower friction coefficient but also show enhanced hardness and wear resistance. Due to solid-solution strengthening, these films generally reach maximum hardness when ternary $\mathrm{Ti}_{x} \mathrm{Zr}_{y} \mathrm{~N}$ contains 60 at.\% $\mathrm{Ti}[3,4]$.

Although preliminary studies on TiZrN films have been conducted in recent years, the properties of TiZrN films have not yet been fully developed; thus, the film properties can be improved by unbalanced magnetron sputtering. DC unbalanced magnetron (UBM) sputtering systems are popular coating systems used to deposit high-quality films of various materials. UBM can reduce the cost of the deposition process [5]. Furthermore, the effect of nitrogen flow rate on the phase transition in TiZrN thin films is worth studying because the phase transformation may change some film properties. Herein, a relatively broad range of process parameters was employed to deposit TiZrN thin films with stable properties. This study primarily aims to investigate the effects of nitrogen flow rate on the structure and properties of TiZrN film depositing using DC unbalanced magnetron sputtering. 
TABLE 1: Deposition conditions of TiZrN thin films.

\begin{tabular}{lc}
\hline Precoating conditions & $6.7 \times 10^{-4} \mathrm{~Pa}$ \\
Base vacuum pressure & $\left(5 \times 10^{-6}\right.$ torr $)$ \\
Bombardment voltage & $-1000 \mathrm{~V}$ \\
Bombardment time & $5 \mathrm{~min}$ \\
Coating conditions & \\
Current density & $\mathrm{Ti}: 0.24 \mathrm{~A}$ \\
& $\mathrm{Zr}: 0.24 \mathrm{~A}$ \\
Working pressure & $0.17 \mathrm{~Pa}$ \\
Substrate bias & $\left(1.3 \times 10^{-3}\right.$ torr $)$ \\
Coating temperature & $-80 \mathrm{~V}$ \\
Deposition time & $400^{\circ} \mathrm{C}$ \\
Ar flow rate & $40 \mathrm{~min}$ \\
$\mathrm{~N}_{2}$ flow rate & $30 \mathrm{sccm}$ \\
\hline
\end{tabular}

\section{Experiments}

TiZrN thin films were deposited on Si substrates using a DC unbalanced magnetron sputtering system. Prior to deposition, the substrate was presputtered in argon atmosphere for $5 \mathrm{~min}$ to remove the surface oxide layer. The substrate was subjected to a bias of $-1000 \mathrm{~V}$ using a power supply, and the argon flow rate was fixed at $50 \mathrm{sccm}$ to clean the substrate surface. The target-to-substrate distance was adjusted to $10 \mathrm{~cm}$. The power supplies of the two targets were operated at $0.24 \mathrm{~A}$. High-purity working and reactive gases were introduced, and mass flow controllers were used to adjust both gases. The flow rate of argon gas (99.9995\%) was fixed at $30 \mathrm{sccm}$ with a maximum gas flow rate of $50 \mathrm{sccm}$. The flow rate of nitrogen gas (99.9995\%) was varied from 0 to $2.5 \mathrm{sccm}$ with a maximum gas flow rate of $5 \mathrm{sccm}$. The negative substrate bias voltage was maintained at $-80 \mathrm{~V}$. The coating temperature was $400^{\circ} \mathrm{C}$. The deposition conditions for nine samples are listed in Table 1.

The crystal structures of the TiZrN films were determined by X-ray diffraction (XRD) using $\mathrm{Cu}-\mathrm{K} \alpha$ radiation, and the cross-sectional microstructures of the TiZrN thin films were observed by field-emission gun-scanning electron microscopy (FEG-SEM). The surface compositions of TiZrN thin films were determined by X-ray photoelectron spectroscopy under a vacuum of $10^{-10}$ torr. The electrical resistivities of the TiZrN film were measured using a four-point probe, and the hardness values were determined by nanoindentation. The residual stress of the specimen deposited on silicon was determined by a laser curvature measurement system that measured the curvatures of a specimen before and after film deposition. The colorations of the TiZrN thin films were examined at room temperature using a Hunterlab MiniScan XE Plus spectrophotometer (Model 4000VSAV).

\section{Results and Discussion}

3.1. Structure. The chemical compositions, crystal structures, residual stresses, and mechanical properties of the TiZrN thin films are summarized in Tables 2 and 3.

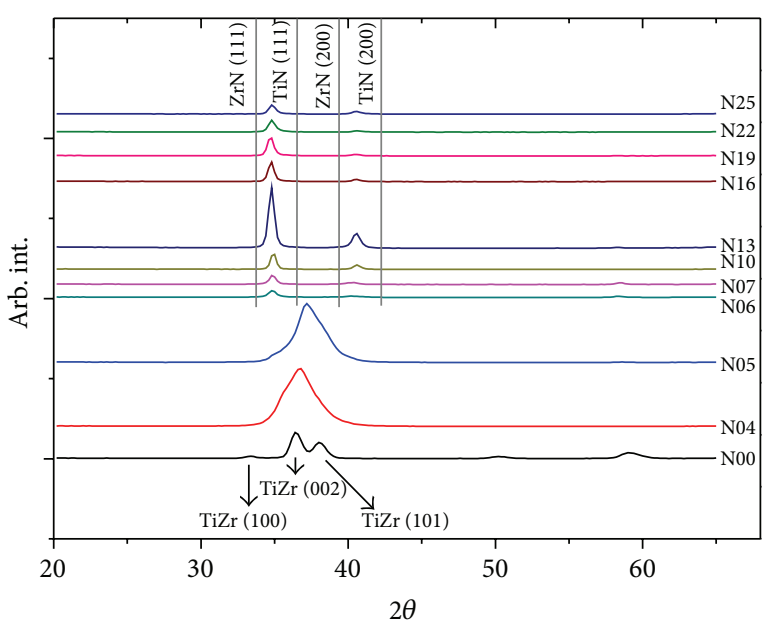

FIgURE 1: XRDs pattern of TiZrN films deposited at different various flow rates.

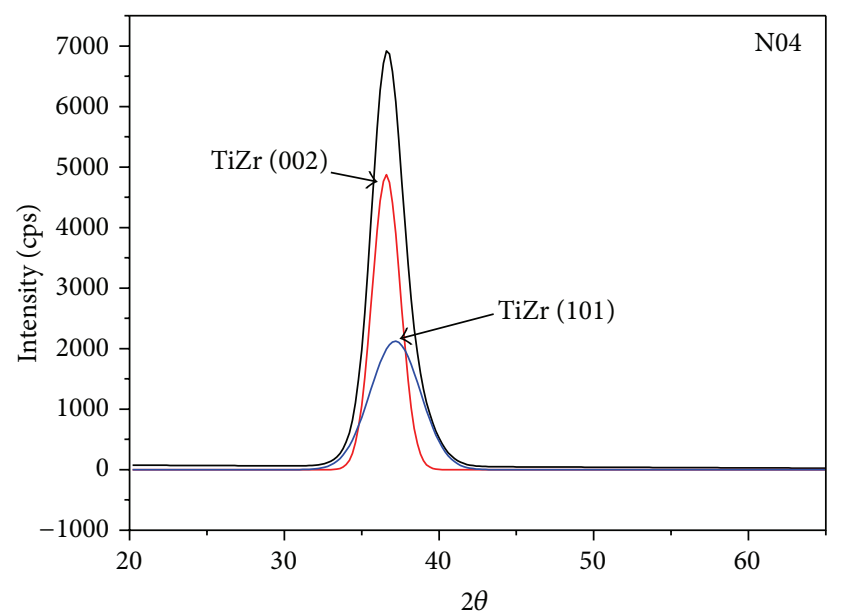

FIgURE 2: Deconvolution patterns of the N04 specimen.

All reflection peaks of TiZr were observed between the $\mathrm{Ti}$ and $\mathrm{Zr}$ peaks in the XRD patterns. Similarly, all reflection peaks of TiZrN were observed between the peaks of TiN and $\mathrm{ZrN}$. Figure 1 shows the XRD patterns of the films deposited at different nitrogen flow rates.

The (100), (002), and (101) crystalline planes of TiZr were found in specimen N00, and the (111) and (200) plane of TiZrN were observed in specimens N06 to N25. Only one broad peak appeared in the spectra of specimens N04 and N05. This unsymmetrical peak can be deconvoluted into two peaks-TiZr (002) and TiZr (101) peaks-as shown in Figures 2 and 3. The XRD results indicate that the phase transition of films occurred as the nitrogen flow rate increased from 0 to $0.6 \mathrm{sccm}$.

The texture coefficients of films N06 to N25 were calculated from the integrated intensities of the TiZrN (111) and TiZrN (200) peaks (Table 2). The intensity of the (111) peak was stronger than that of the (200) peak; thus, the preferred orientation of specimens N06 to N25 was (111). Figure 4 shows the variation in texture coefficient with nitrogen flow 


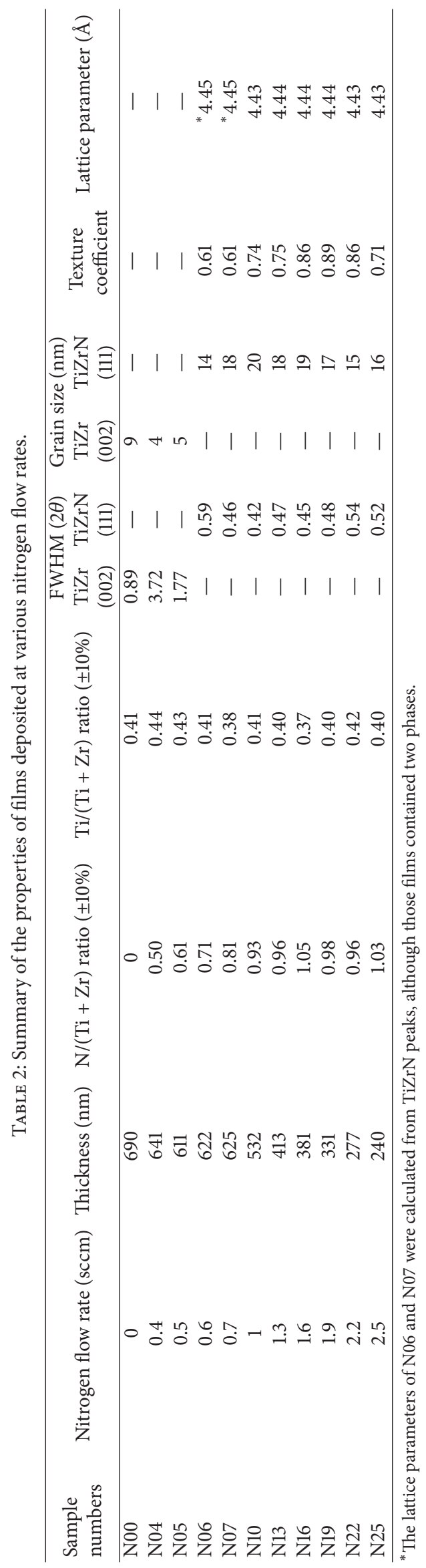


TABLE 3: Colorations, residual stresses, and hardness values of films deposited at various nitrogen flow rates.

\begin{tabular}{|c|c|c|c|c|c|c|c|}
\hline $\begin{array}{l}\text { Sample } \\
\text { numbers }\end{array}$ & Nitrogen flow rate $(\mathrm{sccm})$ & $L^{*}$ & $\begin{array}{l}\text { lorat } \\
a^{*}\end{array}$ & $b^{*}$ & $\begin{array}{l}\text { Residual stress (GPa) } \\
( \pm 2 \%)\end{array}$ & $\begin{array}{l}\text { Hardness (GPa) } \\
( \pm 8 \%)\end{array}$ & $\begin{array}{l}\text { Resistivity } \\
(\mu \Omega \cdot \mathrm{cm})\end{array}$ \\
\hline N00 & 0 & 82.3 & 1.6 & 3.8 & 0.56 & 6 & $110.9 \pm 1.18$ \\
\hline N04 & 0.4 & 79.1 & 1.7 & 4.2 & -0.60 & 19 & $217.9 \pm 6.14$ \\
\hline N05 & 0.5 & 79.7 & 1.9 & 4.4 & -1.63 & 18 & $179.9 \pm 1.39$ \\
\hline N06 & 0.6 & 81.2 & 1.6 & 5.4 & -2.58 & 27 & $132.6 \pm 4.32$ \\
\hline N07 & 0.7 & 83 & 1.6 & 8.14 & -2.97 & 33 & $78.5 \pm 1.11$ \\
\hline N10 & 1 & 83.7 & 3.3 & 28.6 & -5.17 & 35 & $34.8 \pm 1.73$ \\
\hline N13 & 1.3 & 84 & 3.1 & 28.9 & -5.42 & 33 & $35.4 \pm 0.35$ \\
\hline N16 & 1.6 & 84.1 & 3.5 & 29.4 & -5.53 & 37 & $35.7 \pm 0.36$ \\
\hline N19 & 1.9 & 83.7 & 3.3 & 29.6 & -5.21 & 38 & $37.8 \pm 0.42$ \\
\hline N22 & 2.2 & 82.6 & 4.3 & 30.5 & -4.22 & 38 & $38.0 \pm 0.4$ \\
\hline N25 & 2.5 & 82.4 & 4.4 & 30.1 & -3.93 & 38 & $39.7 \pm 0.53$ \\
\hline
\end{tabular}

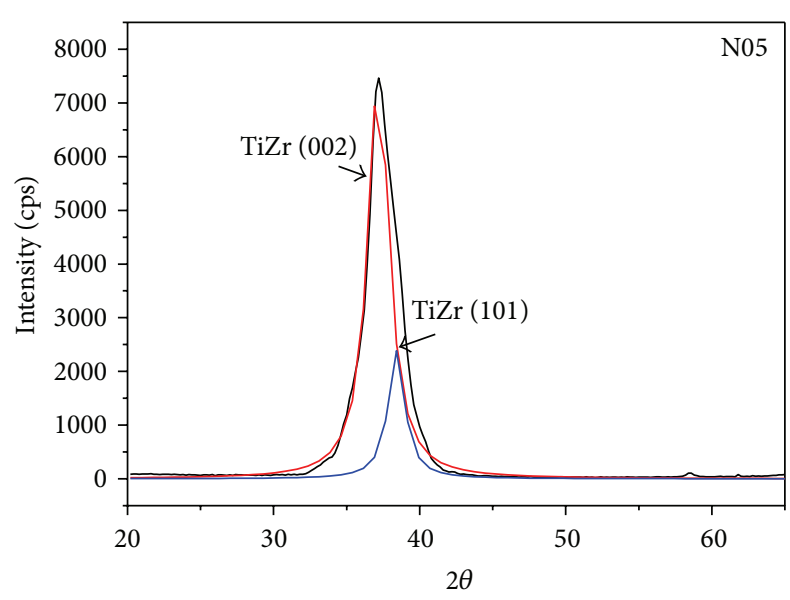

FIGURE 3: Deconvolution patterns of the N05 specimen.

rate. The texture coefficient of (111) increased from 0.6 to 0.9 with increasing nitrogen flow rate from 0.6 to $1.9 \mathrm{sccm}$; as nitrogen flow rates increased from 1.9 to $2.5 \mathrm{sccm}$, the texture coefficient decreased to 0.7.

The full-width-at-half-maximum (FWHM) values of the TiZr (002) or TiZrN (111) peaks were also calculated from the XRD patterns (Table 2). The FWHM of TiZr (002) for specimen N04 was larger than that of specimen N05, indicating the better crystallinity of N05. This suggests that increasing the nitrogen flow rate can improve the crystalline quality of the TiZr phase in TiZrN films. The FWHM of specimen N06 was larger than those of the films deposited at higher nitrogen flow rates, indicating the poor crystallinity of the N06 TiZrN film.

The grain sizes of the films were obtained from the FWHM values of the TiZr (002) or TiZrN (111) peaks using the Scherrer equation (Table 2). The grain sizes of TiZr (002) in specimens N04 and N05 were less than $10 \mathrm{~nm}$. The grain size of TiZrN (111) in specimen N06 was smaller than those for films deposited at higher nitrogen flow rates; for flow rates above $0.7 \mathrm{sccm}$, the average grain size was approximately $18 \mathrm{~nm}$.

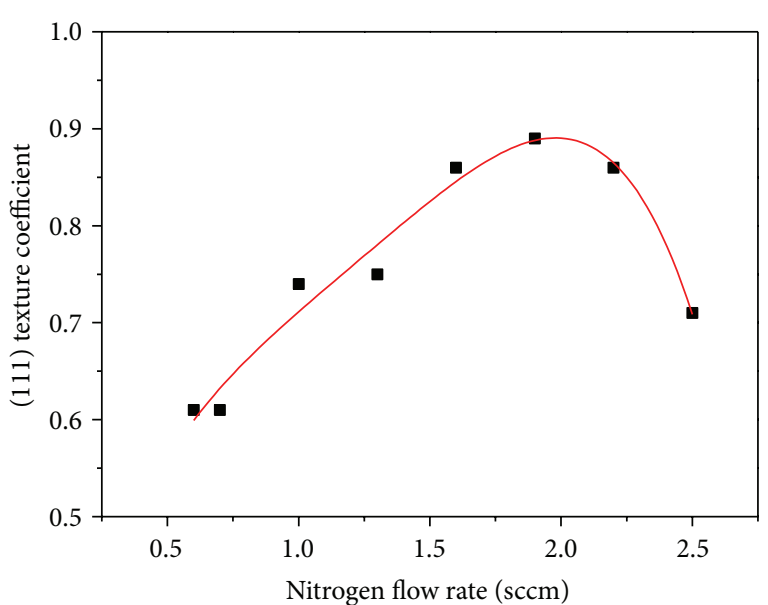

Figure 4: Texture coefficient of the TiZrN films with respect to nitrogen flow rate.

Figures 5(a), 5(b), 5(c), and 5(d) show the GIXRD patterns of specimens N00, N04, N05, and N06, respectively. The X-ray incident angle was $0.5^{\circ}$, and the $2 \theta$ angle scanned from $20^{\circ}$ to $100^{\circ}$. The $2 \theta$ angles of peaks were obtained by fitting each peak on the basis of the assumption of a Gaussian or Lorentz distribution. The GIXRD patterns did not reveal additional phases that were not observed by XRD. Five major peaks of the TiZr crystalline plane, namely, (100), (101), (102), (103), and (200), were observed in the GIXRD pattern of specimen N00. The patterns of specimens N04 and N05 reveal that there were two phases in these films, that is, $\mathrm{TiZr}$ and TiZrN. A single TiZrN phase with five major peaks ((111), (200), (220), (311), and (222)) was observed in the spectrum of specimen N06. The GIXRD patterns of the other specimens were similar to that of N06 at nitrogen flow rates higher than $0.6 \mathrm{sccm}$.

The lattice parameter from each $(h k l)$ plane was calculated by the following equation:

$$
a=\frac{\lambda \times \sqrt{h^{2}+k^{2}+l^{2}}}{2 \times \sin \theta} \quad(\lambda=1.5405 \AA) .
$$




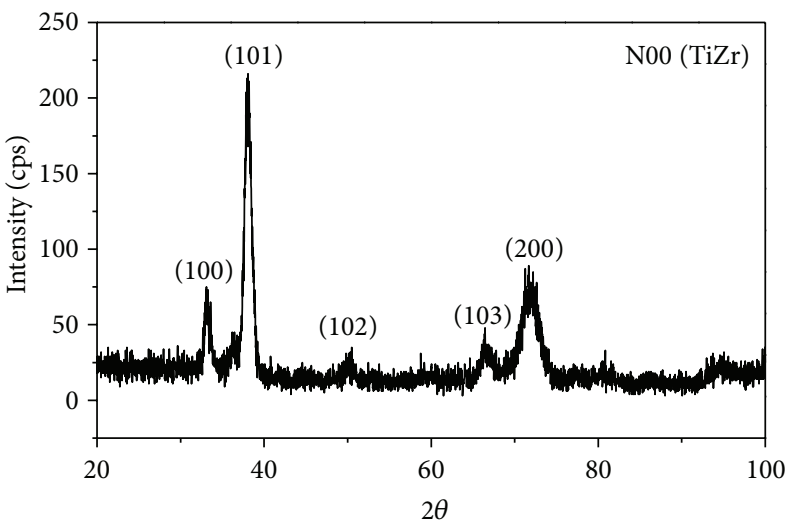

(a)

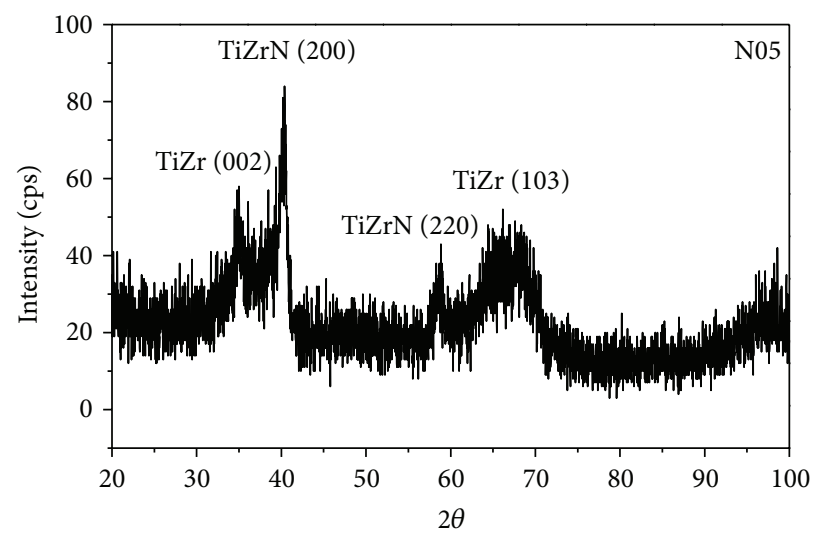

(c)

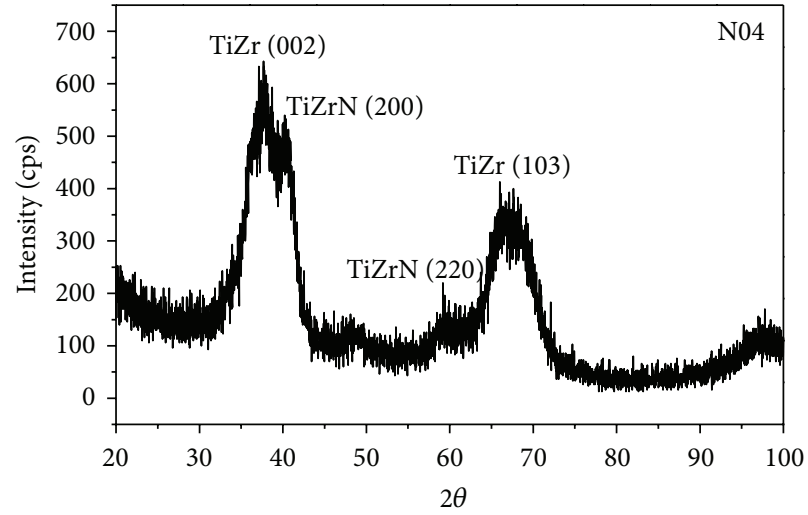

(b)

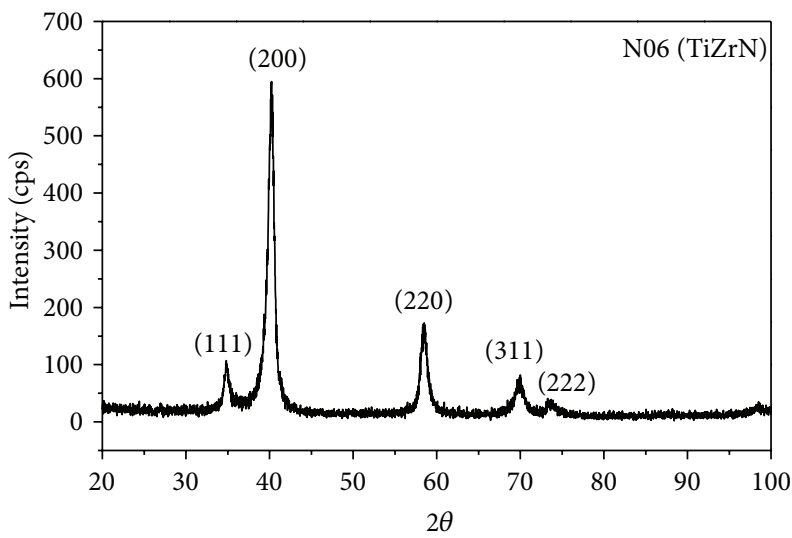

(d)

FIgURE 5: GIXRD patterns of specimens (a) N00, (b) N04, (c) N05, and (d) N06.

The lattice parameter of each peak was plotted against $\cos \theta / \sin \theta$ and linearly fitted. The lattice parameter $\left(a_{0}\right)$ was obtained from extrapolation to $\theta=90^{\circ}$ (Table 2). The lattice parameters of specimens N04 and N05 are not listed since there was just one or two diffraction peaks of each phase in the XRD patterns of these mixed-phase films, which is insufficient for meaningful linear regression. The lattice parameters of films deposited at nitrogen flow rates from 1.0 to $2.5 \mathrm{sccm}$ ranged from 4.43 to $4.44 \AA$ with an error below $0.4 \%$. The lattice parameters were not significantly influenced by the nitrogen flow rate.

Figure 6 shows the cross-sectional SEM images of the samples deposited at different nitrogen flow rates. Although the columnar structure was not evident in the sample deposited at a nitrogen flow rate of $0.4 \mathrm{sccm}$, this structure became more evident with increasing flow rate.

The thicknesses of the TiZrN films ranged from 240 to $690 \mathrm{~nm}$, which decreased with increasing nitrogen flow rate at a constant deposition time of $40 \mathrm{~min}$. The deposition rate was calculated as the thickness divided by the deposition time. The variation in deposition rate with nitrogen flow rate is shown in Figure 7. The deposition rate decreased with increasing nitrogen flow rate, which was likely due to the decrease in the supply of $\mathrm{Ti}$ and $\mathrm{Zr}$ atoms with increasing nitrogen flow rate, thereby reducing the deposition rate.
Figures 8 and 9 show the deconvoluted XPS Zr-3d and Ti-2p spectra for samples N19 and N04, respectively.

The contents of $\mathrm{Ti}, \mathrm{Zr}, \mathrm{N}$, and $\mathrm{O}$ were calculated from the integrated intensities of the deconvolution XPS spectra. The bonding of TiN, TiNO, $\mathrm{TiO}_{2}, \mathrm{ZrN}, \mathrm{ZrNO}$, and $\mathrm{ZrO}_{2}$ may have existed in the TiZrN thin films deposited at nitrogen flow rates exceeding $0.7 \mathrm{sccm}$. When the nitrogen flow rate was less than $0.7 \mathrm{sccm}, \mathrm{Ti}-\mathrm{Ti}$ and $\mathrm{Zr}-\mathrm{Zr}$ metal bonds were present in the TiZrN films.

$\mathrm{The} \mathrm{N} /(\mathrm{Ti}+\mathrm{Zr})$ and $\mathrm{Ti} /(\mathrm{Ti}+\mathrm{Zr})$ ratios were calculated from the integrated areas of each element divided by their sensitive factors (Table 2). All of the $\mathrm{Ti} /(\mathrm{Ti}+\mathrm{Zr}$ ) ratios were approximately 0.4 . The variation in $\mathrm{N} /(\mathrm{Ti}+\mathrm{Zr}$ ) ratio with nitrogen flow rate is shown in Figure 10. The $\mathrm{N} /(\mathrm{Ti}+$ $\mathrm{Zr}$ ) ratio increased from 0.6 to 1 as nitrogen flow rate increased from 0.6 to $1.3 \mathrm{sccm}$ and then leveled off at 1 when nitrogen flow rate increased further. According to the binary phase diagram, the N/Ti ratio of the TiN ranged from 0.6 to 1.2 [6], whereas the $\mathrm{N} / \mathrm{Zr}$ ratio of the $\mathrm{ZrN}$ phase ranged from 0.8 to 1.1 [7]. A low $\mathrm{N} /(\mathrm{Ti}+\mathrm{Zr})$ ratio indicates that the content of nitrogen atoms is insufficient to form a single TiZrN phase; hence, the films with low $\mathrm{N} /(\mathrm{Ti}+\mathrm{Zr})$ ratios contained both $\mathrm{TiZr}$ and $\mathrm{TiZrN}$ or $\mathrm{TiN}$ and $\mathrm{ZrN}$ phases. The GIXRD results also support this argument. 

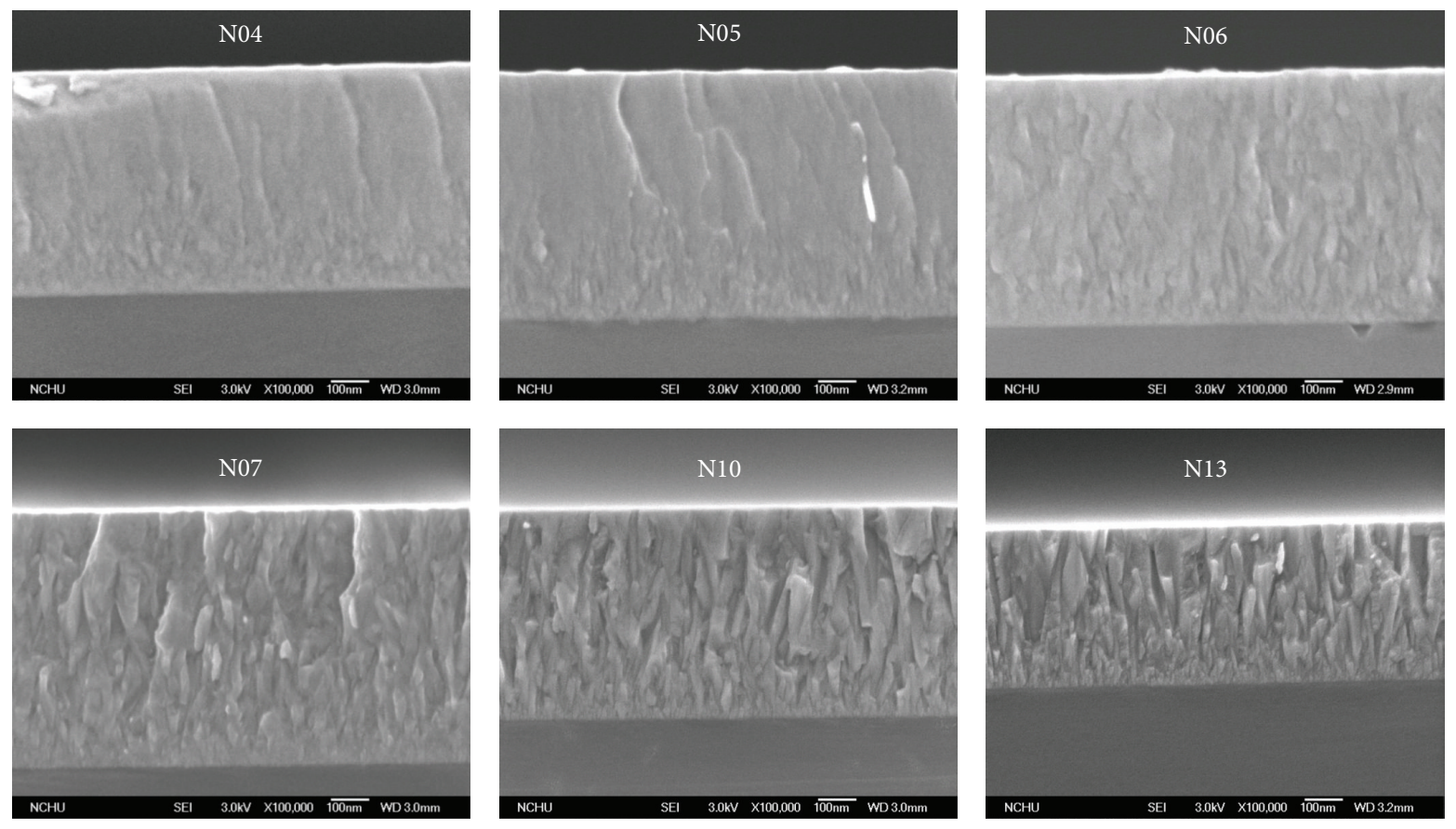

FIgure 6: Cross-sectional SEM images of the TiZrN films.

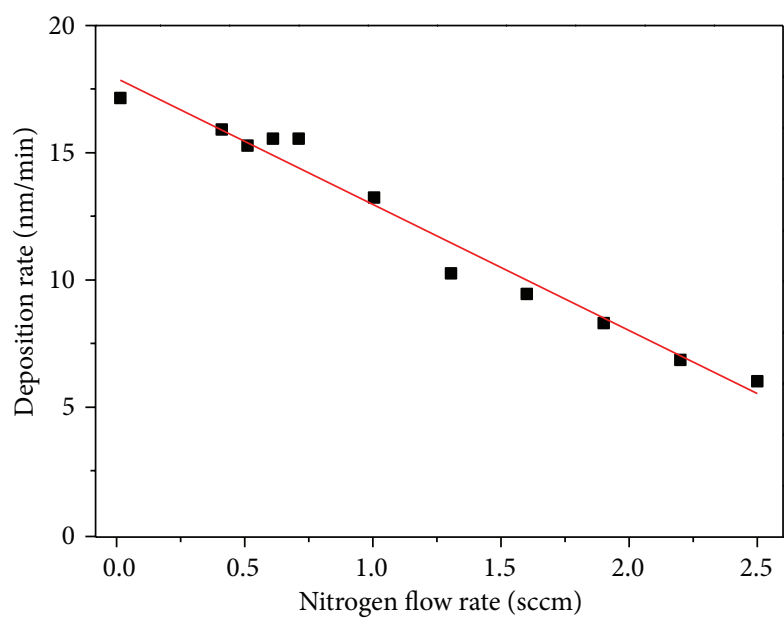

Figure 7: Deposition rate as a function of nitrogen flow rate.

The colorations of all samples determined by spectrophotometry are shown in Figure 11. The samples deposited at nitrogen flow rates less than $1 \mathrm{sccm}$ were gray in color, whereas the samples containing higher nitrogen contents exhibited gold coloration. Note that the N06 and N07 specimens were gray, but only TiZrN peaks were observed in their XRD patterns. This indicates that another phase may have existed in the N06 and N07 specimens.

The average values of $L^{*} a^{*} b^{*}$ located on the color coordinate in the CIELAB 1976 coloration space are listed in Table 3. The relationship between $L^{*} a^{*} b^{*}$ and $\mathrm{N}_{2}$ flow rate is shown in Figure 12. Among the gold-colored samples, the colorations of samples N22 and N25 were slightly different from those of the others. The $a^{*}$ value, which represents the level of red color, increased with increasing nitrogen flow rate. The $L^{*}$ value represents the brightness of the film. The $L^{*}$ values of samples N22 and N25 were smaller than those of the other gold-colored samples, whereas the $a^{*}$ values of these samples were larger. These results indicate that the colorations of samples N22 and N25 were darker gold compared to the other samples.

According to abovementioned results, those specimens can be divided into three zones based on the XRD patterns. Zone 1 is the film with a single TiZr phase at a nitrogen flow rate of $0 \mathrm{sccm}$. Zone 2 is the mixed-phase film; the nitrogen flow rate range of zone 2 was 0.4 to $0.7 \mathrm{sccm}$. Zone 3 is the film containing only the TiZrN phase (nitrogen flow rate $>$ $0.7 \mathrm{sccm})$.

The residual stresses of the TiZrN films were determined using an optical method (Table 3). Tensile stress was observed only in sample N00, whose XRD pattern exhibited TiZr peaks, whereas compressive stress was found in all other films. Figure 13 shows the variation in residual stress with nitrogen flow rate. The compressive stress initially increased with increasing $\mathrm{N}_{2}$ flow rate in zone 2. In zone 3, the stress stabilized as nitrogen flow rate further increased and decreased when nitrogen flow rate exceeded $1.9 \mathrm{sccm}$.

Figure 14 shows the variation in electrical resistivity with nitrogen flow rate. The resistivity rapidly increased to $217.9 \mu \Omega \cdot \mathrm{cm}$ as nitrogen flow rate increased from 0 to $0.4 \mathrm{sccm}$. In zone 2 , the resistivity decreased to $34.8 \mu \Omega \cdot \mathrm{cm}$ with increasing nitrogen flow rate. The resistivity was not significantly influenced by nitrogen flow rate in zone 3 , and the average resistivity was approximately $35 \mu \Omega \cdot \mathrm{cm}$.

The hardness values of the TiZrN films were measured using a nanoindenter. Figure 15 shows the variation in hardness with nitrogen flow rate. In zone 2, the hardness 


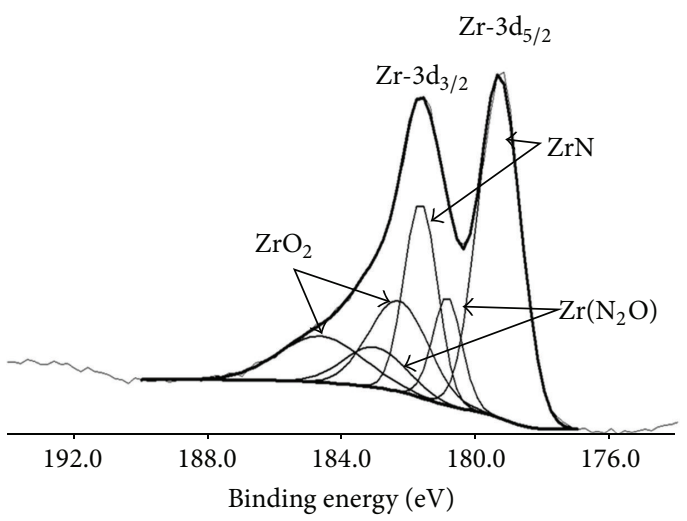

(a)

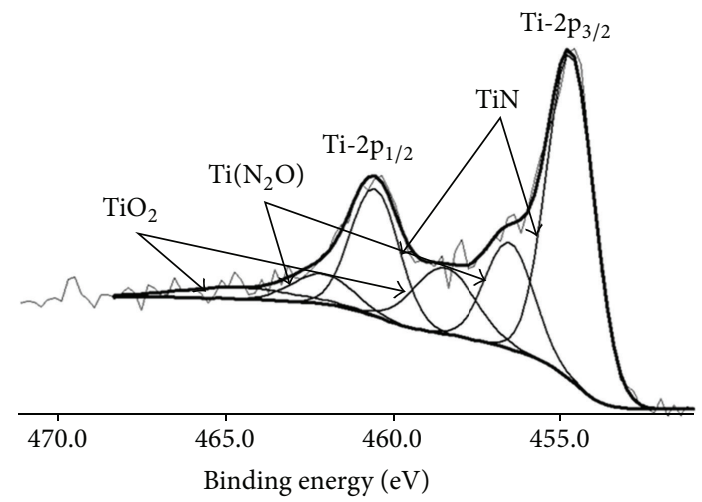

(b)

FIGURE 8: Deconvolution spectra of samples deposited at a nitrogen flow rate of $1.9 \mathrm{sccm}$ : (a) Zr-3d and (b) Ti-2p peaks.

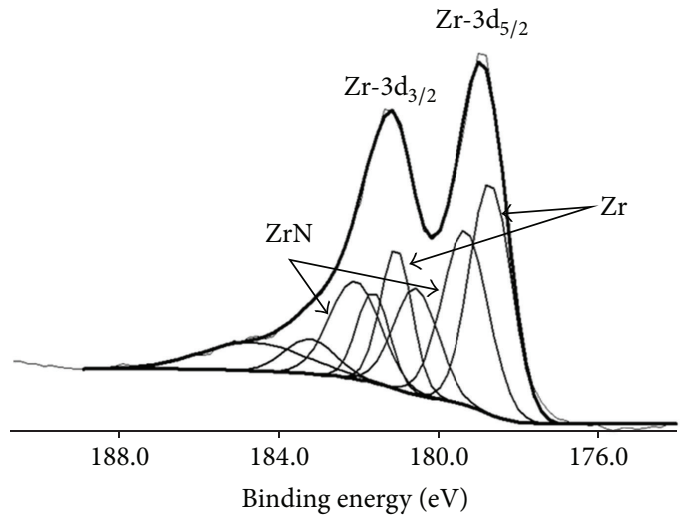

(a)

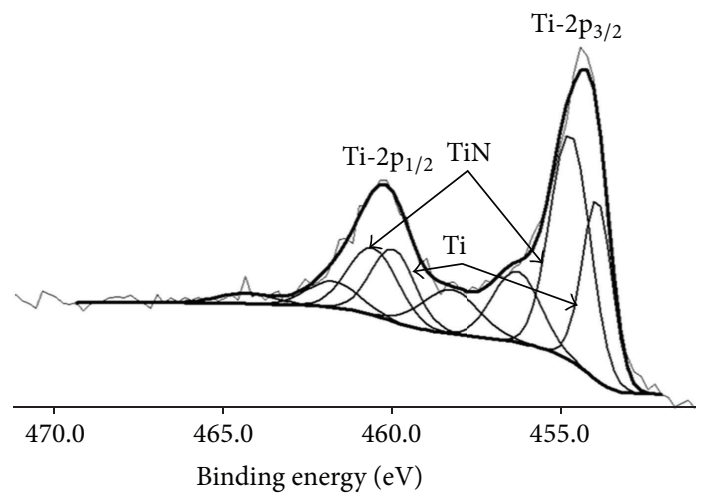

(b)

Figure 9: Deconvolution spectra of sample N06: (a) Zr-3d and (b) Ti-2p.

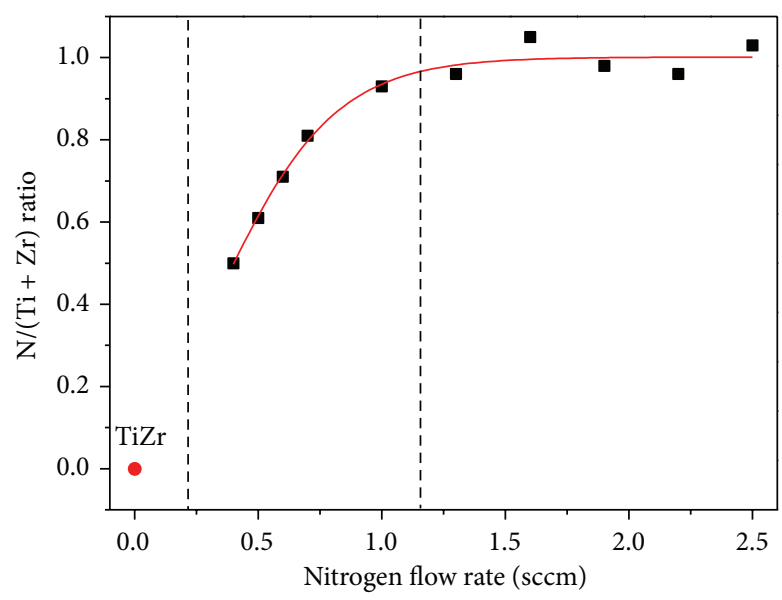

Figure 10: Variation in $\mathrm{N} /(\mathrm{Ti}+\mathrm{Zr})$ with nitrogen flow rate.

increased from 15 to $33 \mathrm{GPa}$ with increasing nitrogen flow rate. In zone 3 , the variation in hardness with nitrogen flow rate was not evident, and the average hardness was approximately $36 \mathrm{GPa}$.
Note that the hardness of the N07 specimen was similar to that of the TiZrN film; however, the N07 specimen was gray in color.

\section{Discussion}

4.1. Nanocomposite. As shown in Figure 1, the XRD peak of TiZr was observed only in specimens N04 and N05 herein; this was not observed in the patterns of specimens N06 and N07. However, the colors of the N04, N05, N06, and N07 films were similar, indicating that the TiZr grains may have been embedded in the TiZrN matrix in specimens N06 and N07. The second phase of TiZr may have been an amorphous phase in N06 and N07; the amorphous phase would not have been found by XRD and GIXRD. Furthermore, the XPS Ti$2 \mathrm{p}_{3 / 2}$ and $\mathrm{Zr}-3 \mathrm{~d}_{5 / 2}$ deconvolution spectra (Figure 8 ) indicated that pure $\mathrm{Ti}$ and $\mathrm{Zr}$ metal bonds existed in specimen N06, further supporting the idea that TiZr was present in the films. According to the phases of TiZrN thin films, the films can be separated into three zones:

(1) Single phase with HCP structure TiZr; N/(Ti $+\mathrm{Zr})=$ 0 (sample N00). 


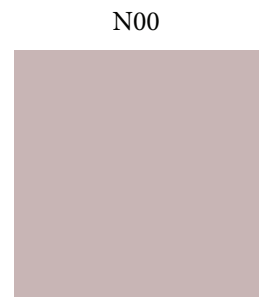

Gray

N10

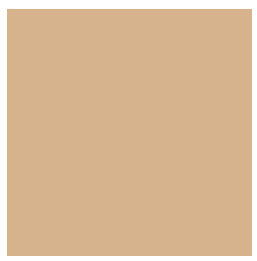

Gold

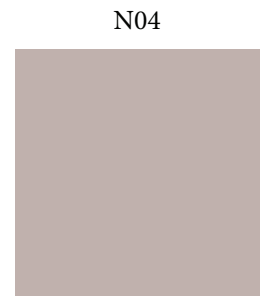

Gray

N13

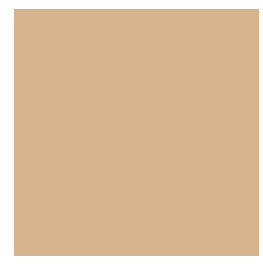

Gold

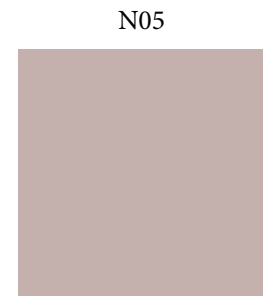

Gray

N16

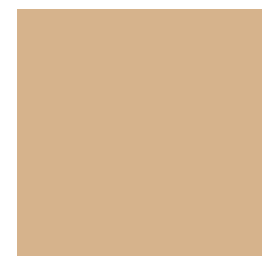

Gold

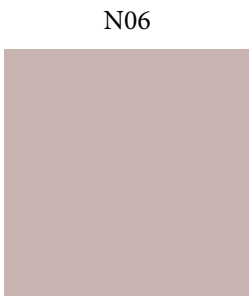

Gray

N19

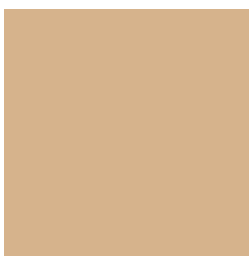

Gold

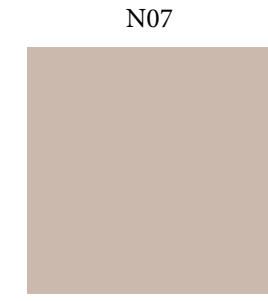

Gray

N22

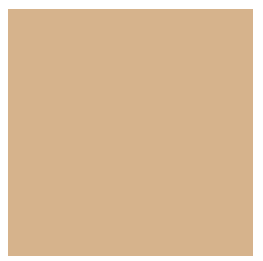

Gold

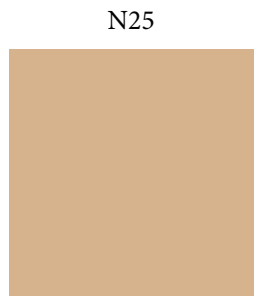

Gold

FIgURE 11: Coloration of all samples used in this study.
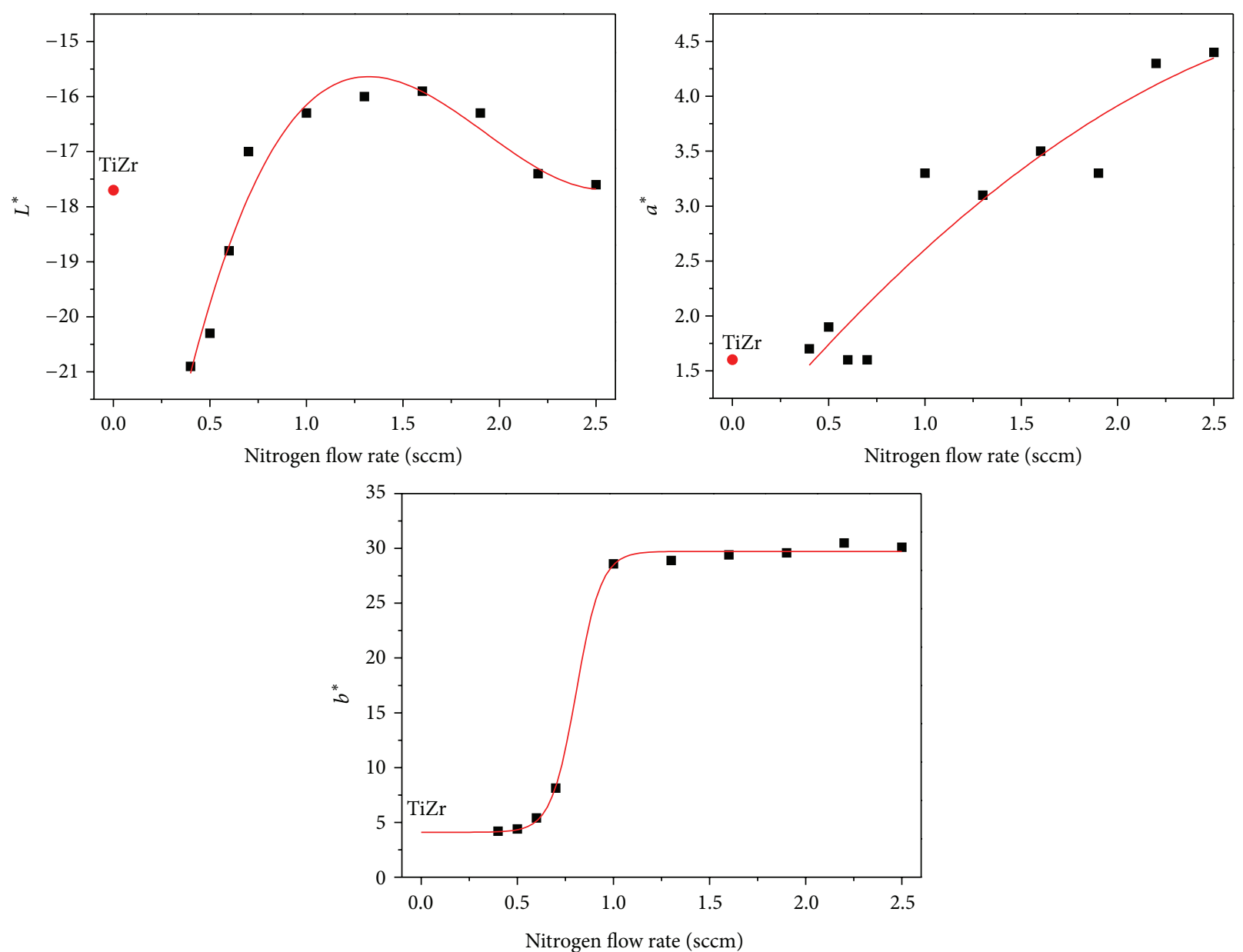

FIgURE 12: Variation in the $L^{*} a^{*} b^{*}$ value with nitrogen flow rate. 


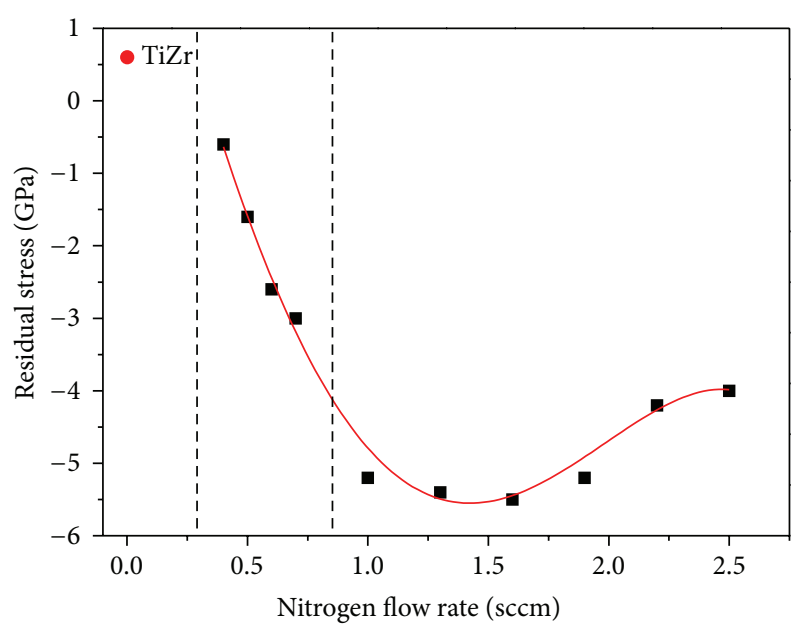

FIgURE 13: Residual stress of TiZrN films as a function of nitrogen flow rate.

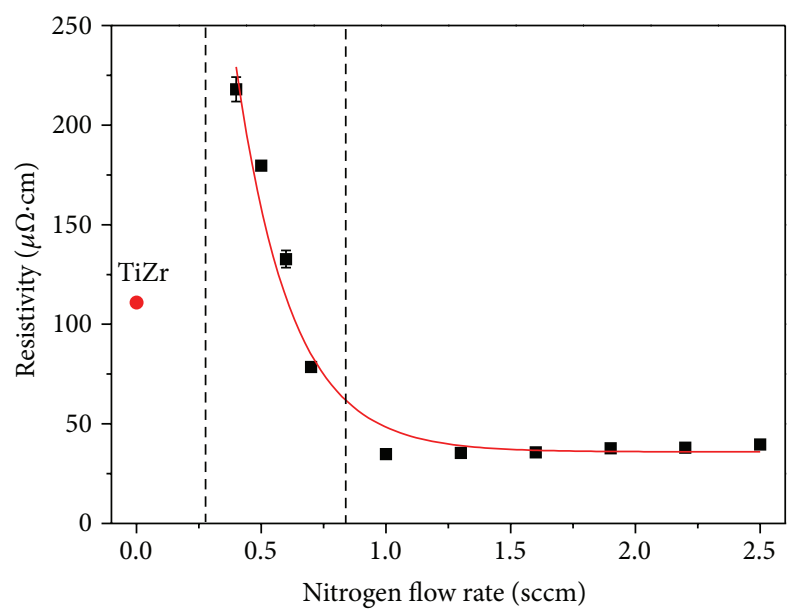

FIgURE 14: TiZrN resistivity as a function of nitrogen flow rate.

(2) Multiphase with HCP structure TiZr, FCC structure TiZrN, and other uncertain phases; $\mathrm{N} /(\mathrm{Ti}+\mathrm{Zr})<0.9$ (samples N04 to N07).

(3) Single phase with FCC structure TiZrN; N/(Ti + Zr) $>0.9$ (samples N10 to N25).

On the basis of this classification scheme, it can be found that the multiphase appeared in the $(\mathrm{Ti}, \mathrm{Zr}) \mathrm{N}$ as the $\mathrm{N} /(\mathrm{Ti}+$ $\mathrm{Zr}$ ) was less than 0.9 on one hand. On the other hand, the $\mathrm{N} /(\mathrm{Ti}+\mathrm{Zr})$ ratio of the stable TiZrN must have been larger than 0.9 . The stable composition of $(\mathrm{Ti}, \mathrm{Zr}) \mathrm{N}$ should consider the contribution of $\mathrm{TiN}$ and $\mathrm{ZrN}$ phases. Based on the N$\mathrm{Ti}$ and $\mathrm{N}-\mathrm{Zr}$ phase diagrams $[6,7]$, the N/Ti composition range of $\mathrm{TiN}$ is $0.6-1.2$ and the $\mathrm{N} / \mathrm{Zr}$ composition range of $\mathrm{ZrN}$ is $0.8-1.1$. In the (Ti, $\mathrm{Zr}) \mathrm{N}$ system, the addition of $\mathrm{Zr}$ to $\mathrm{TiN}$ (or the addition of $\mathrm{Ti}$ to $\mathrm{ZrN}$ ) causes the lattice strain and destroys the stable structure. This lattice strain affects the extent of nitrogen solvation in the solid solution of $(\mathrm{Ti}, \mathrm{Zr}) \mathrm{N}$; thus, the extent of solvation of the stable $(\mathrm{Ti}, \mathrm{Zr}) \mathrm{N}$ films is lesser than those of $\mathrm{TiN}$ and $\mathrm{ZrN}$. The $\mathrm{N} /(\mathrm{Ti}+\mathrm{Zr})$ ratio of

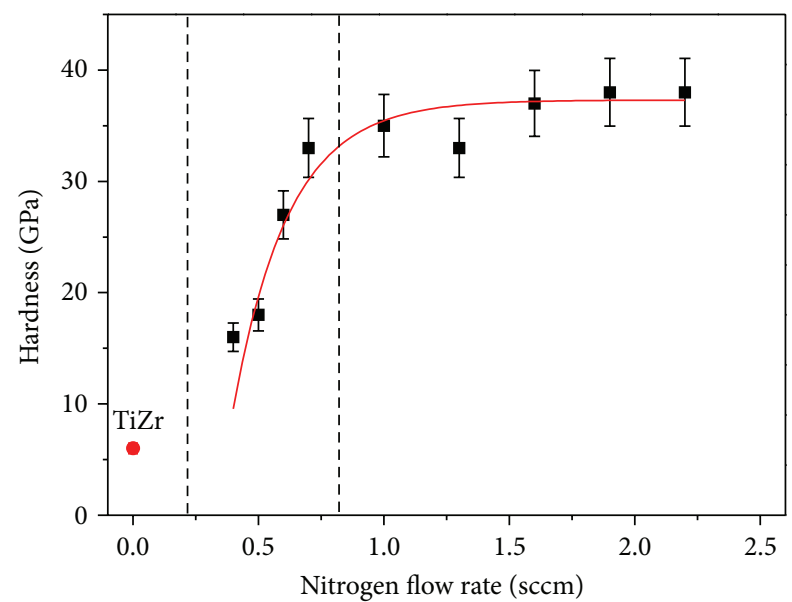

FIgURE 15: TiZrN film hardness as a function of nitrogen flow rate.

stable ( $\mathrm{Ti}, \mathrm{Zr}$ ) N is between 0.8 and 1.1. Nitrogen content of plays an important role in the phase transition. At nitrogen flow rates less than $0.7 \mathrm{sccm}$, the $\mathrm{N} /(\mathrm{Ti}+\mathrm{Zr})$ values of the TiZrN films were less than 0.9 , and there were insufficient nitrogen atoms to bond with the $\mathrm{Ti}$ and $\mathrm{Zr}$ atoms that arrived at the substrate surface; the excess $\mathrm{Ti}$ and $\mathrm{Zr}$ atoms formed the metallic TiZr phase. Thus, the TiZrN film with low N/(Ti $+\mathrm{Zr}$ ) ratio was basically composed of TiZrN and TiZr with a nanocomposite structure. In a previous study, the secondary phase TiZr appeared in TiZrN films with low $\mathrm{N} /(\mathrm{Ti}+\mathrm{Zr})$ ratios [8].

4.2. Hardness. As shown in Figure 15, the hardness of $\mathrm{TiZr}$ film was the lowest among all samples, and that of TiZrN films increased with nitrogen flow rate until $0.7 \mathrm{sccm}$; above this value, the hardness leveled off at approximately $36 \mathrm{GPa}$. Many factors might affect film hardness, such as preferred orientation, grain size, stoichiometry, and residual stress.

Several studies have reported that the (111) texture coefficient is an important factor affecting the hardness of TiN films because $\langle 111\rangle$ is the hardest orientation in $\operatorname{TiN}[9,10]$. Since the Schmid factor for the (111) direction of TiN is zero in all slip systems, hardness increases with increasing (111) texture coefficient. TiZrN has the same $\mathrm{NaCl}$ crystal structure as $\mathrm{TiN}$, (111), which is supposed to be the hardest orientation of the TiZrN film. However, the effect of the (111) texture coefficient on the hardness of the TiZrN film was not significant herein.

In this study, the relationship between grain size and hardness was insignificant. At low nitrogen flow rate, both crystalline and amorphous phases may have formed in the film. Therefore, it was difficult to determine whether the grain size affected film hardness since grain size was measured from XRD patterns, reflecting only crystalline phases.

Differences in composition can significantly affect film hardness. Among the films used herein, the film containing only the metallic TiZr phase, which was deposited without nitrogen, had the lowest hardness. The hardness values of metallic materials are generally lower than those of ceramic materials because ionic and covalent bonds are stronger than 


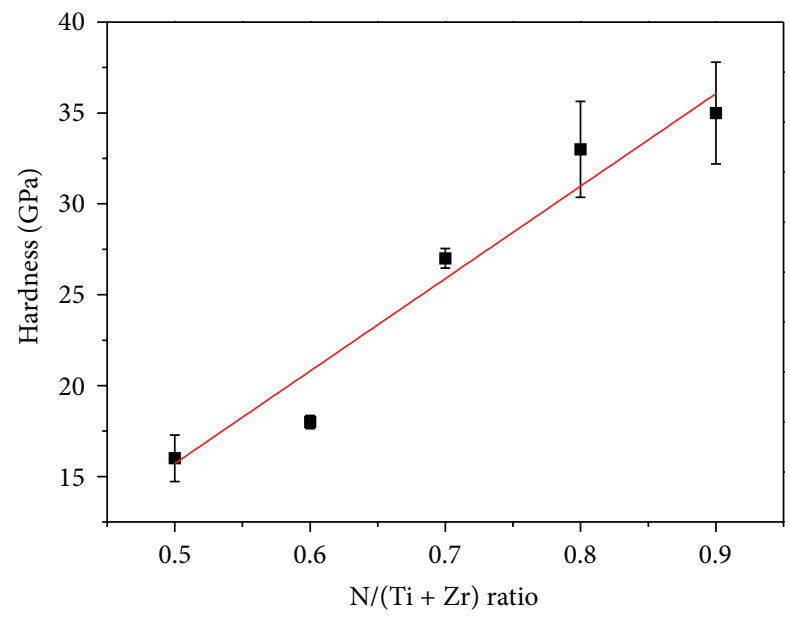

Figure 16: Hardness values of TiZrN films (N04-N10) with respect to $\mathrm{N} /(\mathrm{Ti}+\mathrm{Zr})$ ratio.

metallic bonds. Therefore, the hardness of the TiZr film was lower than that of the TiZrN film. The hardness values of TiZrN films were higher than those of TiN and $\mathrm{ZrN}$ due to solid-solution hardening. The addition of $\mathrm{Zr}$ to $\mathrm{TiN}$ (Ti to $\mathrm{ZrN}$ ) induced the lattice distortion of the matrix; hence, it is necessary to apply more force for dislocation slip. Moreover, film hardness is related to the fraction of the TiZrN phase. When nitrogen atoms are introduced during the deposition process, the nitrogen atoms combine with $\mathrm{Ti}$ and $\mathrm{Zr}$ atoms to form the TiZrN phase in the films. In a previous study, the lattice parameter was found to be proportional to the atomic fraction $x$ in $\mathrm{Ti}_{1-x} \mathrm{Zr}_{x} \mathrm{~N}$ [11]. The lattice parameters of the TiZrN films used herein were almost identical, even for the films deposited at low nitrogen flow rates of 0.6 and $0.7 \mathrm{sccm}$. This result indicates that the compositions of the TiZrN phases in the films were identical. In this case, the overall compositional change comes from the surrounding TiZr phase. Therefore, we can assume that the increase in $\mathrm{N} /(\mathrm{Ti}$ $+\mathrm{Zr}$ ) ratio is equivalent to increase in the TiZrN fraction. As the nitrogen flow rate increased, more nitrogen atoms bonded with $\mathrm{Ti}$ and $\mathrm{Zr}$ atoms to form the high-hardness TiZrN phase. In other words, the $\mathrm{N} /(\mathrm{Ti}+\mathrm{Zr})$ ratio increased with increasing nitrogen flow rate from 0.4 to $1.0 \mathrm{sccm}$, and the TiZrN film hardness increased with increasing TiZrN fraction (Figure 16).

In zone 3 , the $\mathrm{N} /(\mathrm{Ti}+\mathrm{Zr})$ ratios of the TiZrN films were larger than 0.8 and were with stable nitrogen flow rate; thus, the TiZrN film hardness did not vary with nitrogen flow rate. The averaged hardness was approximately $36 \mathrm{GPa}$ at high nitrogen flow rates ranging from 1.0 to $2.5 \mathrm{sccm}$. Notably, although the N/Zr ratio was below 0.9 in specimen N07 with a nanocomposite structure, its high hardness was similar to that of the TiZrN film. It is possible that the structure of specimen N07 was composed of uniform composite phases.

4.3. Resistivity. The resistivity of TiZr is approximately $126 \mu \Omega \cdot \mathrm{cm}$. TiZrN can be used as a diffusion barrier due to its low resistivity $(60-100 \mu \Omega \cdot \mathrm{cm})[12,13]$.

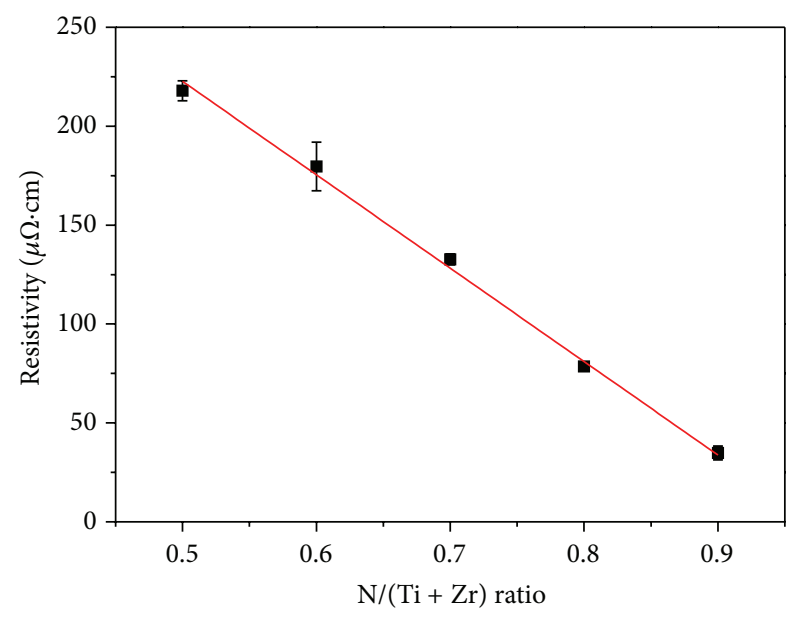

FIgURE 17: TiZrN film (N04-N10) resistivity with respect to the $\mathrm{N} /(\mathrm{Ti}+\mathrm{Zr})$ ratio.

Resistivity depends on lattice defects and impurity atoms in the film; increases in lattice defects and impurity atoms increase the scattering of conductive free electrons and decrease the mean free path of conductive free electrons. Thus, more lattice defects and impurity atoms may increase the resistivity. Herein, the resistivities of the nanocomposite films deposited at low nitrogen flow rates $(0.4$ to $0.7 \mathrm{sccm})$ are higher than those of the single-phase TiZr and TiZrN films (Figure 14). This may indicate that more lattice defects and impurity atoms were present at the TiZr/TiZrN interfaces in the nanocomposite films, resulting in higher resistivities compared to the single-phase films. The FWHM from XRD patterns represents the crystallinity of the crystal plane in the films, and the FWHM of each specimen was calculated from different peaks. Therefore, we could not confirm if the crystallinity was related to TiZrN film resistivity.

The TiZrN film resistivity decreased with increasing nitrogen flow rate to $0.9 \mathrm{sccm}$ (Figure 14). TiZrN resistivity may have depended upon of $\mathrm{N} /(\mathrm{Ti}+\mathrm{Zr})$, as shown in Figure 17. The films deposited at low nitrogen flow rates ( 0.4 to $0.7 \mathrm{sccm}$ ) exhibited nanocomposite structures; hence, the resistivities of these films were higher than those of the films deposited at high nitrogen flow rates. The fraction of TiZrN phase was also related to TiZrN film resistivity. As nitrogen flow rate increased from 0.4 to $1.0 \mathrm{sccm}$, the $\mathrm{N} /(\mathrm{Ti}+\mathrm{Zr})$ ratio increased accordingly, and the structures of TiZrN films became uniform. Therefore, the resistivity decreased with increasing $\mathrm{N} /(\mathrm{Ti}+\mathrm{Zr})$ ratio at low nitrogen flow rate. The lowest TiZrN film resistivity values were observed at nitrogen flow rates above $1.0 \mathrm{sccm}$, which may be attributed to the single-phase TiZrN film.

Comparing the results of a previous study with those herein indicates that low resistivity and high hardness can be obtained at high nitrogen flow rates. This may be due to the high crystallinity of the TiZrN structure.

4.4. Residual Stress. The residual stress in the TiZr film was tensile stress, whereas compressive stress was observed 


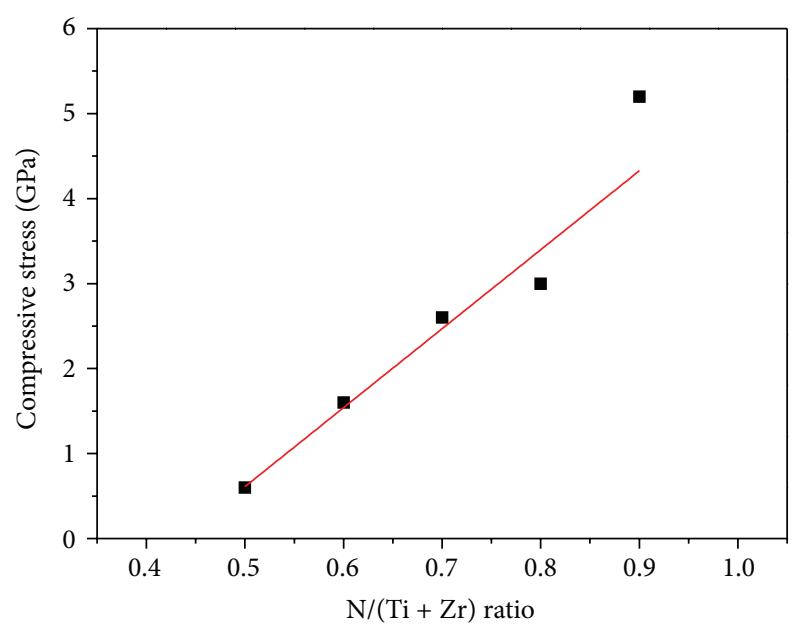

FIgure 18: Residual stress of the TiZrN films (N04-N10) as a function of $\mathrm{N} /(\mathrm{Ti}+\mathrm{Zr})$.

in TiZrN films. Residual stress comes from thermal stress and grown-in stress. Herein, the major contribution was grown-in stress. Substrate temperature, gas pressure, and substrate bias are known to be the main parameters affecting grown-in stress. Herein, the substrate temperature and bias were fixed at $400^{\circ} \mathrm{C}$ and $-80 \mathrm{~V}$, respectively. There was an evident relationship between the residual stress of TiZrN and nitrogen flow rate.

Figure 13 shows that the compressive stress of the TiZrN films decreased with increasing nitrogen flow rate from 0.4 to $1.0 \mathrm{sccm}$. The $\mathrm{N} /(\mathrm{Ti}+\mathrm{Zr})$ ratio increased as the nitrogen flow rate increased, whereas the residual stress decreased because the stress was released with the appearance of the TiZr phase. Therefore, the fraction of TiZr phase in the films decreased with increasing $\mathrm{N} /(\mathrm{Ti}+\mathrm{Zr})$ ratio, and the compressive stress in the film consequently increased. As shown in Figure 18, the compressive stress increased with increasing $\mathrm{N} /(\mathrm{Ti}+\mathrm{Zr})$ ratio for the films deposited at nitrogen flow rates ranging from 0.4 to $1.0 \mathrm{sccm}$.

The residual stress in the TiZrN films increased to $-5 \mathrm{GPa}$ as nitrogen flow rate increased to $1.0 \mathrm{sccm}$ and then stabilized. However, the residual stress decreased as nitrogen flow rate increased from 0.22 to $0.25 \mathrm{sccm}$. There was no significant relationship between residual stress and any structural properties.

\section{Conclusions}

(1) Nanocrystalline TiZrN thin films were successfully prepared by DC unbalanced magnetron sputtering with different nitrogen flow rates ranging from 1.0 to $2.5 \mathrm{sccm}$. The hardness and resistivity stabilized when nitrogen flow rate increased above $1.0 \mathrm{sccm}$.

(2) According to the phases of the TiZrN thin films, three zones were defined. The film exhibited a single phase with TiZr HCP structure at nitrogen flow rate of zero. As the nitrogen flow rate increased from 0.4 to $0.7 \mathrm{sccm}$, the films were two-phase with TiZr of
HCP structure and $\mathrm{TiZrN}$ of $\mathrm{NaCl}$ structure. When nitrogen flow rate was higher than $1.0 \mathrm{sccm}$, the films were single-phase with $\mathrm{TiZrN}$ of $\mathrm{NaCl}$ structure.

(3) The $\mathrm{N} /(\mathrm{Ti}+\mathrm{Zr})$ ratio of the TiZrN single-phase film must be larger than 0.8 , and the $\mathrm{N} /(\mathrm{Ti}+\mathrm{Zr})$ ratio did not change with nitrogen flow rate when the flow rate exceeded $1.0 \mathrm{sccm}$.

(4) The hardness and residual stress of the TiZrN films increased with increasing $\mathrm{N} /(\mathrm{Ti}+\mathrm{Zr})$ ratio when the nitrogen flow rate increased from 0.4 to $1.0 \mathrm{sccm}$. In contrast, the resistivity of the TiZrN films decreased with increasing $\mathrm{N} /(\mathrm{Ti}+\mathrm{Zr})$ ratio.

\section{Conflict of Interests}

The authors declare that there is no conflict of interests regarding the publication of this paper.

\section{References}

[1] A. S. Korhonen, J. M. Molarius, I. Penttinen, and E. Harju, "Hard transition metal nitride films deposited by triode ion plating," Materials Science and Engineering, vol. 105-106, no. 2, pp. 497501, 1988.

[2] L. P. Ward, K. N. Strafford, C. Subramanian, and T. P. Wilks, "Observations on the structure, hardness and adhesion properties of a selection of multicomponent refractory element nitride coatings," Journal of Materials Processing Technology, vol. 56, no. 1-4, pp. 375-384, 1996.

[3] L. A. Donohue, J. Cawley, and J. S. Brooks, "Deposition and characterisation of arc-bond sputter $\mathrm{Ti}_{x} \mathrm{Zr}_{y} \mathrm{~N}$ coatings from pure metallic and segmented targets," Surface and Coatings Technology, vol. 72, no. 1-2, pp. 128-138, 1995.

[4] V. V. Uglov, V. M. Anishchik, V. V. Khodasevich et al., "Structural characterization and mechanical properties of $\mathrm{Ti}-\mathrm{Zr}$ $\mathrm{N}$ coatings, deposited by vacuum arc," Surface and Coatings Technology, vol. 180-181, pp. 519-525, 2004.

[5] P. J. Kelly and R. D. Arnell, "Magnetron sputtering: a review of recent developments and applications," Vacuum, vol. 56, no. 3, pp. 159-172, 2000.

[6] H. A. Wriedt and J. L. Murray, "The N-Ti (Nitrogen-Titanium) system," Bulletin of Alloy Phase Diagrams, vol. 8, no. 4, pp. 378388, 1987.

[7] H. Okamoto, "N-Zr (Nitrogen-Zirconium)," Journal of Phase Equilibria and Diffusion, vol. 27, no. 5, p. 551, 2006.

[8] Y.-W. Lin, J.-H. Huang, and G.-P. Yu, "Microstructure and corrosion resistance of nanocrystalline TiZrN films on AISI 304 stainless steel substrate," Journal of Vacuum Science and Technology A, vol. 28, article 774, 2010.

[9] H. Ljungcrantz, M. Odén, L. Hultman, J. E. Greene, and J.E. Sundgren, "Nanoindentation studies of single-crystal (001)-, (011)-, and (111)-oriented TiN layers on MgO," Journal of Applied Physics, vol. 80, no. 12, pp. 6725-6733, 1996.

[10] W.-J. Chou, G.-P. Yu, and J.-H. Huang, "Deposition of TiN thin films on $\mathrm{Si}(100)$ by HCD ion plating," Surface and Coatings Technology, vol. 140, no. 3, pp. 206-214, 2001.

[11] Q. Y. Chen, Characterization of structure and mechanical properties of nano-crystalline TiZrN films deposited by unbalanced magnetron sputtering: the effect of Ti and $\mathrm{Zr}$ target current [M.S. thesis], National Tsing Hua University, Hsinchu, Taiwan, 2012. 
[12] C. Lee and Y.-L. Kuo, "The evolution of diffusion barriers in copper metallization,” JOM, vol. 59, no. 1, pp. 44-49, 2007.

[13] Y. L. Kuo, F. C. Kung, and T. L. Su, "Superior stability of ultrathin and nanocrystalline TiZrN films as diffusion barriers for $\mathrm{Cu}$ metallization," Nanoscience and Nanotechnology Letters, vol. 1, no. 1, pp. 37-41, 2009. 

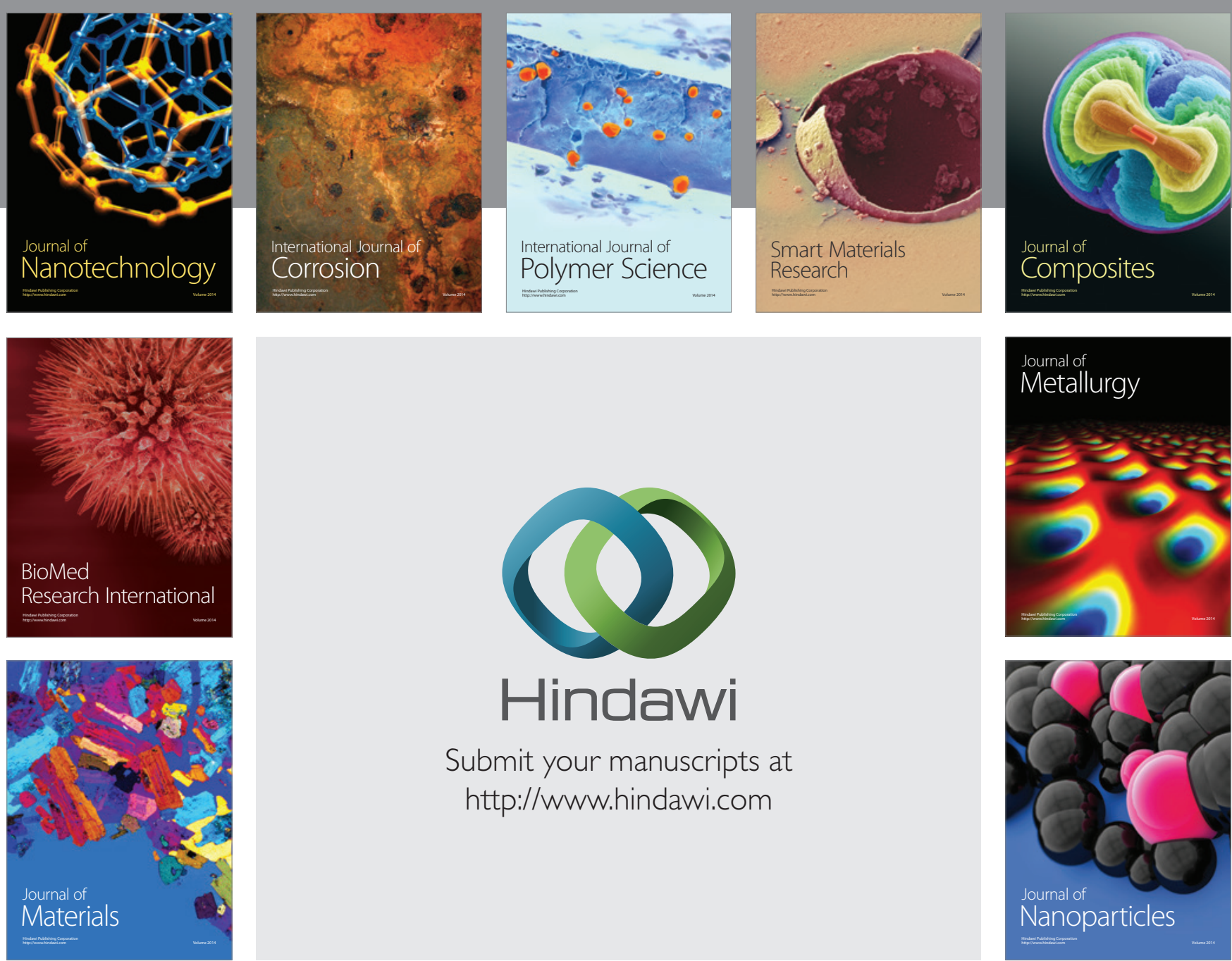

\section{Hindawi}

Submit your manuscripts at

http://www.hindawi.com

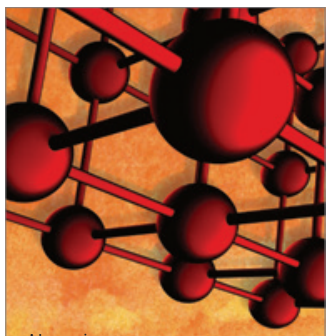

Materials Science and Engineering
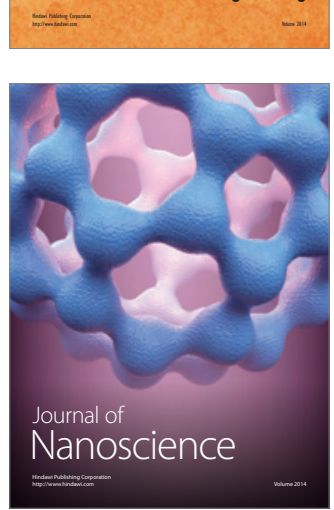
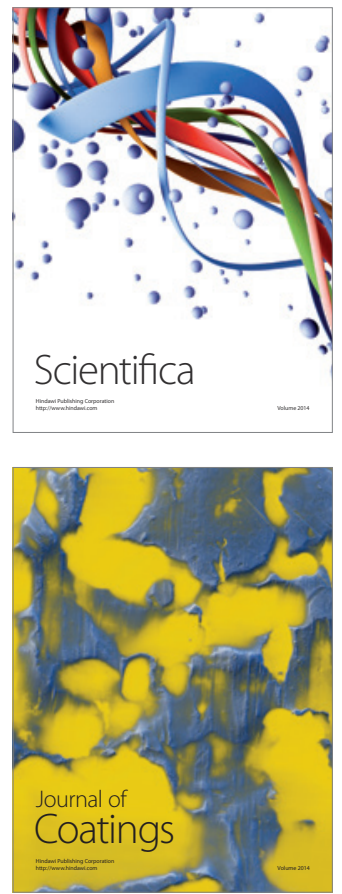
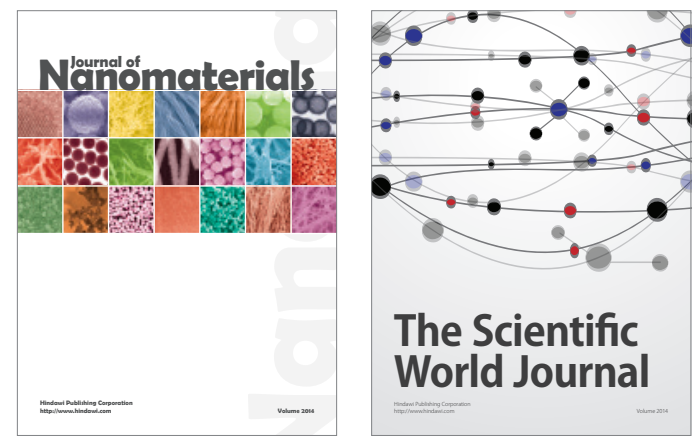

The Scientific World Journal
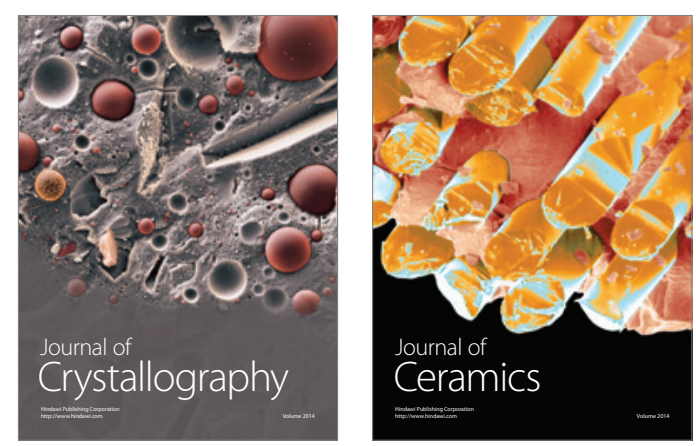
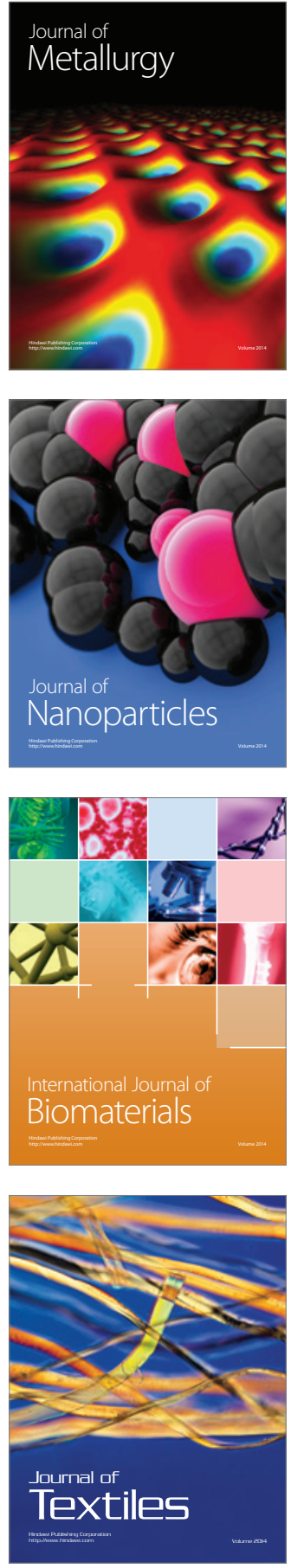